\title{
Adenosine-Induced Coronary Artery Spasm: A Case Report
}

\author{
Montaser Ismail Nidal Asaad Jassim Al-Suwaidi \\ Department of Cardiology and Cardiac Surgery, Hamad Medical Corporation, Doha, Qatar
}

\section{Key Words}

Adenosine $\cdot$ Coronary spasm · Angina

\begin{abstract}
Objective: To describe an uncommon complication of intravenous adenosine administration. Clinical Presentation and Intervention: A 41-year-old female patient presented with palpitations due to supraventricular tachycardia. The patient was treated with intravenous adenosine with resolution of the tachycardia. Subsequently, the patient developed chest pain and ST segment elevation in the inferior leads that resolved with sublingual nitroglycerin. Conclusion: This report showed a case of coronary spasm secondary to the administration of adenosine. We therefore recommend that discretion be exercised when giving adenosine, especially to patients with an underlying tendency for vasospastic reactions.

Copyright $\odot 2011$ S. Karger AG, Basel
\end{abstract}

\section{Introduction}

The two main indications of adenosine administration are pharmacological stress myocardial scintigraphy (vasodilatation effect) and supraventricular tachyarrhythmia (SVT) termination known as atrioventricular blocking effect. Both dipyridamole and adenosine vasodilators have been used in pharmacological stress tests.
Adenosine is a potent coronary vasodilator with a very short half-life. However, paradoxical coronary vasospasm has been described for both [1]. While coronary spasm has been a reported side effect of the dipyridamole stress test since the 1980s [1], adenosine-induced coronary spasm was not described before 2004 when it was reported in the USA $[2,3]$. The first case reported in the UK was in 2006 [4], while in France and Japan the first reported cases were found in $2008[5,6]$.

In previous case reports, coronary spasm was triggered by intravenous adenosine infusion during a pharmacological stress test. Herein we present a case of adenosine-induced coronary spasm after an intravenous bolus dose for SVT termination.

\section{Case Report}

A 41-year-old Sri Lankan female housemaid, without prior cardiovascular diseases, presented to the Emergency Room at Hamad General Hospital, Doha, Qatar, on November 17, 2009, with intermittent palpitations and chest pain of 2 days' duration. The latest episode was associated with mild dyspnea and started few hours prior to the time of presentation. There was no history of syncopal or presyncopal episodes. Upon arrival, the patient was still having palpitations and chest discomfort, was fully conscious, oriented, mildly dyspneic and not in respiratory distress. Upon examination, blood pressure was $105 \mathrm{~mm} \mathrm{Hg}$ systolic and $65 \mathrm{~mm} \mathrm{Hg}$ diastolic; the patient was tachycardiac with a heart rate of 200 beats/min (tachycardia is defined as heart rate more than 100 beats/min). Apart from tachycardia, cardiovascular examination, respiratory, neurological and abdominal examinations were

\section{KARGER}

Fax +4161306 1234

E-Mail karger@karger.ch

www.karger.com
(C) 2011 S. Karger AG, Basel

1011-7571/12/0211-0082\$38.00/0

Accessible online at:

www.karger.com/mpp
Nidal Asaad

Department of Cardiology and Cardiovascular Surgery

Hamad General Hospital

PO Box 3050, Doha (Qatar)

E-Mail nidalasaad@gmail.com 
Fig. 1. Electrocardiogarm at the time of presentation, demonstrating narrow complex SVT with a rate of 203 beats/min.
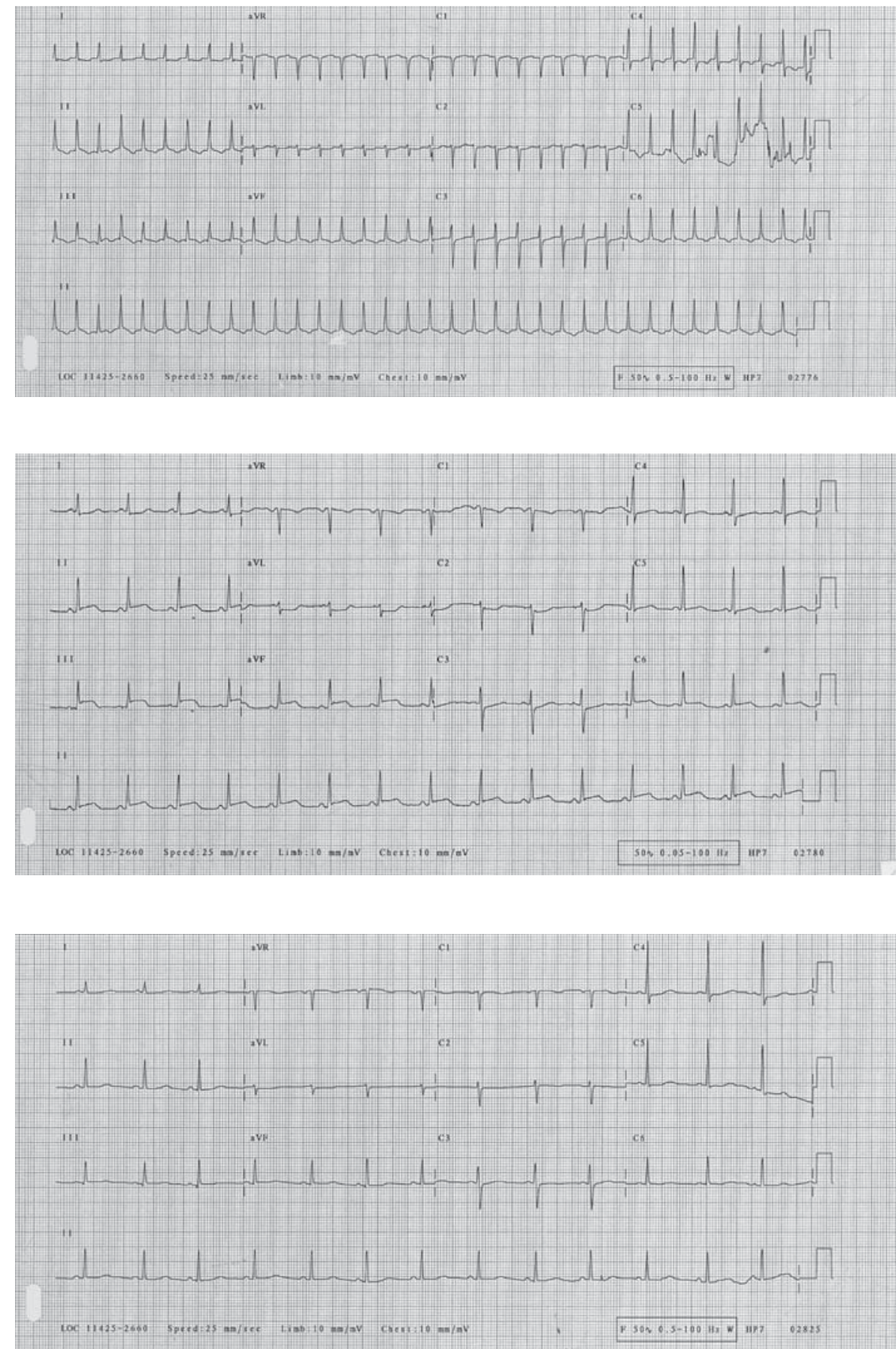

Fig. 3. 12-lead ECG after nitroglycerin, showing sinus rhythm with resolution of the ST segment changes.
Fig. 2. Electrocardiogram after intravenous administration of adenosine, revealing normal sinus rhythm ST segment elevation in the inferior leads and V6 and reciprocal ST segment depression on leads V2, 3 and $\mathrm{aVL}$. unremarkable. An electrocardiogram showed narrow complex tachycardia (SVT) with a ventricular rate of 203 beats/min (fig. 1). A vagal stimulation maneuver was attempted to convert the rhythm but was unsuccessful. Subsequently, a bolus of $6 \mathrm{mg}$ adenosine was administered intravenously with successful conversion to sinus rhythm. Repeat electrocardiography demonstrated normal sinus rhythm with significant ST segment elevation in the inferior leads and reciprocal ST depression in leads I, aVL and
V2 (fig. 2). At this point, the patient was still having chest discomfort slightly severer than before. The patient was treated with sublingual $0.5 \mathrm{mg}$ of nitroglycerin, and repeated electrocardiography demonstrated resolution of the ST segment changes (fig. 3) with a marked relief of her symptoms. The patient was subsequently admitted to the Coronary Care Unit and treated with intravenous anticoagulants, antiplatelet agents (aspirin and clopidogrel), isosorbide dinitrates and diltiazem. In laboratory investigations, se- 
rial troponin $\mathrm{T}$ levels were $0.24,0.35$ and $0.28 \mathrm{ng} / \mathrm{ml}$ (normal $<0.01$ ). The remainder of the evaluations were within the normal range. Transthoracic echocardiography revealed hypokinetic segments in the inferolateral areas of the left ventricle with left ventricular ejection fraction of 50\%, normal valves and normal pericardium. Coronary angiography was subsequently performed on the second day and demonstrated patent coronary vessels. Subsequently, the patient underwent successful ablation of the slow pathway of the atrioventricular nodal reentrant tachycardia. The patient was eventually discharged home and since the episode has had no recurrences of symptoms.

\section{Discussion}

This case demonstrated an unusual complication of intravenous administration of adenosine, coronary artery spasm. Both clinical (chest pain) and electrocardiographic (ST segment elevation) evidence of ischemia were reported immediately after adenosine administration, both of which were reverted by sublingual nitrates in this patient. The normal coronary angiography ruled out an atherosclerotic etiology (plaque rupture) as the cause of the patient's ischemia. Vasospastic etiology of the right coronary artery was the most probable explanation of the transient ST elevation in the inferior leads, which was reverted by the antispastic effect of nitroglycerin.

Adenosine acts on adenosine receptors in the sinoatrial node, the atrioventricular node, the coronary arteries and ventricular myocytes, having a vasodilator effect on the coronary microcirculation and a negative chronotropic action. Adenosine has been used in both indications (pharmacological stress test and SVT) with an excellent safety profile. Though rare, coronary vasospasm has been reported and documented as an adverse effect of the dipyridamole stress test [1]. However, adenosineinduced coronary vasospasm has only recently been reported $[2,3]$.

Coronary spasm is thought to be indirectly a result of the abrupt withdrawal of the short-acting vasodilator effect of adenosine [5]. This is added to a predisposition of vulnerable vessels (coronary hypersensitivity). However, the exact mechanism of coronary vasospasm is still unclear $[7,8]$. The role of the autonomic nervous system is controversial. Adenosine stimulates baroreceptors by the vasodilator and hypotensive effect, which in turn leads to sympathetic activation and increased plasma catecholamine concentration [9], and this can trigger the coronary spasm. On the other hand, the endothelium releases both vasodilator and vasoconstrictive factors. The final reaction is thought to be determined by the ultimate balance of action of those factors.

Most of the other reported side effects of adenosine such as flushing, headache, nausea, chest pain or discomfort and shortness of breath are mild and transient in nature [3]. However, more significant adverse effects, which are described more with intravenous adenosine infusion, have been reported rarely. These include cardiac complications such as significant hemodynamic heart block, asystole, hypotension, atrial fibrillation (upon termination of SVT), and more malignant arrhythmias such as torsades de pointes, ventricular tachycardia, ventricular fibrillation and potential cardiac arrest. Significant noncardiac complications include bronchospasm and potential respiratory arrest, dizziness, increased intracranial pressure and seizures [5]. Previously documented cases in the literature report coronary spasm that was induced by intravenous infusion of adenosine during a pharmacological stress test [2-6], involving the anterior, lateral and inferior territories. In our case, the spasm was induced by a bolus dose of adenosine (6 mg i.v.) given for SVT termination, and it involved the inferior (right coronary) territory. Other potential causes for chest pain and transient ST segment elevation in this patient are unlikely. First, spontaneous chest pain did not precede the palpitations in this patient but only occurred after adenosine infusion. She has been asymptomatic since ablation therapy, making spontaneous coronary spasm less likely $[10,11]$. Second, although vagally mediated coronary spasm has been described in the literature very rarely $[11,12]$, almost all of those patients had vagal symptoms prior to the onset of chest pain. On the other hand, the current patient did not have vagal symptoms and in fact the vagal maneuver was unsuccessful in terminating the arrhythmia; moreover, the chest pain and ECG changes only occurred after adenosine infusion.

\section{Conclusion}

This report showed a case of coronary spasm secondary to the administration of adenosine. We therefore recommend that discretion be exercised when giving adenosine, especially to patients with an underlying tendency for vasospastic reactions. 


\section{References}

$>1$ L'Abbate A, Picano E, Lattanzi F, Masini M, Distante A: Aminophylline termination of dipyridamole stress as a trigger of coronary vasospasm in variant angina. Am J Cardiol 1988;62:694-697.

-2 Golzar J, Mustafa SJ, Movahed A: Chest pain and ST-segment elevation 3 min after completion of adenosine pharmacologic stress testing. J Nucl Cardiol 2004;11:744-746.

3 Weissman G, Scandrett RM, Howes CJ, Russell RR 3rd: Coronary vasospasm during an adenosine stress test. J Nucl Cardiol 2004;11: 747-750.

4 Faganello G, Belham M: Coronary vasospasm during an adenosine stress test. Int J Cardiol 2006;113:E84-E86.
5 Rosenberg T, Perdrisot R: Coronary spasm after adenosine stress test: an adverse effect of a vasodilator. Acta Cardiol 2008;63:401404.

6 Nakayama M, Morishima T, Chikamori T, Aiga M, Takazawa K, Yamashina A: Coronary arterial spasm during adenosine myocardial perfusion imaging. J Cardiol 2009; 53:288-292.

7 Lagerqvist B, Sylvén C, Waldenström A: Lower threshold for adenosine-induced chest pain in patients with angina and normal coronary angiograms. Br Heart J 1992; 68:282-285.

8 Inobe $\mathrm{Y}$, Kugiyama K, Morita E, Kawano H, Okumura K, Tomiguchi S, Tsuji A, Kojima A, Takahashi M, Yasue H: Role of adenosine in pathogenesis of syndrome $\mathrm{X}$ : assessment with coronary hemodynamic measurements and thallium-201 myocardial single-photon emission computed tomography. J Am Coll Cardiol 1996;28:890-896.
9 Biaggioni I, Killian TJ, Mosqueda-Garcia R, Robertson RM, Robertson D: Adenosine increases sympathetic nerve traffic in humans. Circulation 1991;83:1668-1675.

10 Al Suwaidi J, Velianou JL, Gertz M, Holmes DR, Cannon RO, Higano ST, Lerman A: Systemic amyloidosis presenting with angina pectoris. Ann Intern Med 1999;131:838-841.

-11 Al Suwaidi J, Higano ST, Holmes DR, Lerman A: Pathophysiology, diagnosis, and current management strategies for chest pain in patients with normal findings on angiography. Mayo Clin Proc 2001;76:813-822.

12 Osborn LA, Reynolds B: Vagally mediated multivessel coronary artery spasm during coronary angiography. Cathet Cardiovasc Diagn 1998;44:423-426. 